\title{
Role of Systemic Agrobacterium tumefaciens Populations in Crown Gall Incidence on the Walnut Hybrid Rootstock 'Paradox'
}

\author{
L. E. Yakabe, S. R. Parker, and D. A. Kluepfel, United States Department of Agriculture-Agricultural Research Service, Crops \\ Pathology and Genetics Research Unit, Davis, CA 95616
}

\begin{abstract}
Yakabe, L. E., Parker, S. R., and Kluepfel, D. A. 2012. Role of systemic Agrobacterium tumefaciens populations in crown gall incidence on the walnut hybrid rootstock 'Paradox'. Plant Dis. 96:1415-1421.

Greater than $75 \%$ of English walnut production in the United States occurs on the walnut rootstock Juglans hindsii $\times J$. regia 'Paradox', which is highly susceptible to infection by Agrobacterium tumefaciens. When seed were germinated and grown in the presence of A. tumefaciens, in the absence of wounding, $94 \%$ of the seedlings exhibited tumors while $89 \%$ contained systemic A. tumefaciens populations. When seedlings were wound inoculated, A. tumefaciens established endophytic populations in stem tissue and often migrated from the site of infection. Distribution of A. tumefaciens in the stem was random

and may exhibit seasonal variation. A. tumefaciens populations in root tissue were more readily detected than in stem tissue and may serve as a reservoir for subsequent infection of the aerial portions of the tree. Importantly, $7 \%$ of inoculated, asymptomatic seedlings contained endophytic populations of $A$. tumefaciens. In all, $17 \%$ of seedlings inoculated as seeds developed galls at secondary stem-wound sites. These results provide an ecological and epidemiological foundation upon which to modify existing tree-handling practices in both nursery and orchard production environments to manage crown gall incidence.
\end{abstract}

California walnut growers are responsible for $99 \%$ of walnut production in the United States (11). Approximately $75 \%$ of the industry uses the hybrid rootstock Juglans hindsii $\times J$. regia 'Paradox' (C. Leslie, personal communication), which is highly susceptible to crown gall $(1,11,24,30)$. Crown gall has been cited by the walnut industry as one of the top diseases affecting walnut nursery and orchard plantings across all growing regions in California (D. Ramos, personal communication).

Crown gall incidence on walnut trees has been related to soilborne populations of Agrobacterium tumefaciens which colonize and infect root and crown tissue resulting in hypertrophic and hyperplastic growth visualized as galls $(11,24,30)$. For this reason, the California walnut industry relies on preplant fumigation of orchard and nursery soils to manage soilborne populations of $A$. tumefaciens. Cultural practices also have been modified to reduce tree wounds and improve post-cold-storage handling of planting stock, which serves to limit infection by A. tumefaciens $(11,30)$. Unfortunately, despite these efforts, crown gall control has been inconsistent.

Recent observations by nurserymen and farm advisors support the hypothesis that walnut trees harbor systemic populations of $A$. tumefaciens. Supporting evidence includes high crown gall incidence on seedlings grown in methyl-bromide-fumigated nursery blocks. This is significant because methyl bromide fumigation has been shown to be effective in reducing A. tumefaciens populations in soil (43). In a recent crown gall outbreak, galls were initially observed at wounds incurred during the grafting process but, after digging the trees, galls also were observed on the crown and roots. There was a strong correlation between galls occurring at graft wounds and additional galls occurring on the roots and crown $(P=$

\section{Corresponding author: D. A. Kluepfel, E-mail: dakluepfel@ucdavis.edu}

The United States Department of Agriculture is an equal opportunity provider and employer.

Accepted for publication 22 February 2012

http://dx.doi.org/10.1094/PDIS-05-11-0364-RE

This article is in the public domain and not copyrightable. It may be freely reprinted with customary crediting of the source. The American Phytopathological Society, 2012.
0.0003), suggesting a systemic source of inoculum (data not shown). Orchard managers also report high crown gall incidence in 1- to 3-year-old orchards planted with seemingly clean nursery stock.

Agrobacterium spp. have been shown to move systemically in several hosts such as chrysanthemum, tomato, sunflower, grape, and cherry $(4,5,9,12,19,20,31,35,39,46)$. A. vitis colonization and movement throughout the vascular system of asymptomatic grapevines is perhaps the best understood example. Galls develop only when damage to the scion creates a wound where members of the systemic population are available to infect $(15,16,38)$. Gall formation caused by systemic A. tumefaciens populations are rare in species of Rosa but may be common in Chrysanthemum, depending on the cultivar $(14,20,27)$. Endophytic populations of $A$. tumefaciens also have been noted in naturally infested walnut by Cubero et al. (9), while Miller et al. (21) indicate that artificially introduced endophytic A. rhizogenes populations are low and present little disease risk. Determination of the source, frequency, and disease risk of systemic A. tumefaciens populations in walnut trees is essential for development of effective crown gall management.

In grape production systems, infested grapevine cuttings are the primary inoculum source of $A$. vitis infections but $A$. vitis-free grapevines also can be contaminated by infested soil (28). Studies examining A. tumefaciens systemic populations in Rose and Chrysanthemum spp. reported that primary infections were initiated from external wounding and inoculation of plant stems and, occasionally, from seed or seedlings planted in infested soil or artificial growth media $(14,19,27)$. Pionnat et al. (27) suggested that the high-throughput propagation methods in rose production also encourage transfer of $A$. tumefaciens to clean stock via grafting tools. A. tumefaciens transmission via grafting tools also has been demonstrated in walnut (44). It is unknown whether any or all of these sources of inoculum facilitate development of systemic populations of A. tumefaciens in Paradox rootstocks.

The hypothesis that $A$. tumefaciens can establish systemic populations in asymptomatic walnut rootstocks is based on previous reports in other hosts and current field observations of nursery and field-grown walnut trees. Reported here are the results of investigations into the involvement of systemic populations of $A$. tumefaciens biovar 1 in crown gall incidence on Paradox rootstock. Surface-infested seed, infested soil, and infested grafting tools 
were investigated as sources of inoculum. Elucidation of the epidemiology of A. tumefaciens in nursery and orchard conditions will aid in the development of consistent and cost-effective crown gall management strategy.

\section{Materials and Methods}

Bacterial inoculum. The wild-type parent, A. tumefaciens biovar 1 strain 186, was isolated from a surface-sterilized stem section of a walnut seedling with crown gall symptoms in Stanislaus County, CA. A rifampicin-resistant mutant of 186, designated 186r, was used in these experiments and described previously (44). Except for growth in the presence of rifampicin, 186r was indistinguishable from its wild-type parent in terms of antibiotic resistance profiles, growth rate, and pathogenicity on Datura stramonium and Paradox walnut seedlings.

Inoculum was prepared by suspending a $3-\mu$ loop of a $48 \mathrm{~h}$-culture of A. tumefaciens 186r grown on trypticase soy broth (TSB) agar amended with rifampicin sulfate at $100 \mathrm{ppm}$ (TSBA+rif) in 3 $\mathrm{ml}$ of TSB. This was then added to 2 liters of TSB in a Fernbach flask and incubated at $28^{\circ} \mathrm{C}$ on a rotary shaker $(200 \mathrm{rpm})$ for $48 \mathrm{~h}$. Bacterial suspensions were centrifuged at $5,468 \times g$ for $10 \mathrm{~min}$. The resulting pellets were washed twice with sterile water and adjusted spectrophotometrically (DU800 Spectrophotometer; Beckman Coulter, Fullerton, CA) to approximately $10^{8} \mathrm{CFU} / \mathrm{ml}$ (optical density at $600 \mathrm{~nm}=0.1$ ). Soilborne $186 \mathrm{r}$ populations were confirmed by dilution plating on TSBA+rif.

Plant material. Paradox seed used in the seed inoculation experiment were collected from Northern California black walnut (J. hindsii) mother trees pollinated by English walnut (J. regia) trees. The mother trees were grown in a nursery in Colusa County, CA. The seed were dehulled and surface sterilized with $20 \%$ bleach for $10 \mathrm{~min}$ and rinsed with 10 volumes of distilled water before being packaged in plastic bags with moist, steam-pasteurized peat moss and stratified at $4^{\circ} \mathrm{C}$ for 90 days.

Seedlings used in the seedling inoculation experiment were grown from Paradox seed collected in Yolo County, CA. Seed were stratified as described above except without dehulling and grown in steam-pasteurized potting medium in cone-tainers $(3.8$ by $21 \mathrm{~cm}$; Ray Leach Cone-tainer Nursery, Canby, OR) for 1 year outdoors and fertilized as needed. They were transplanted into 18-by-18-by$36-\mathrm{cm}$ pots filled with steam-pasteurized potting medium for an additional year to produce 2 year-old seedlings.

All seedlings in all experiments were confirmed Paradox hybrids using identifying morphological features $(11,30)$. This facilitated culling black walnut seedlings which resulted from selfing of the mother tree.

Seed inoculation experiment. To determine the effects of surface-inoculated seed on the establishment of systemic A. tumefaciens populations in production nurseries, stratified seed were immersed in a solution of $186 \mathrm{r}\left(3 \times 10^{7} \mathrm{CFU} / \mathrm{ml}\right)$ or sterilized, distilled water $\left(\mathrm{sdH}_{2} \mathrm{O}\right)$ for $15 \mathrm{~h}$. Only seed with split shells were selected for use to ensure contact of the inoculum with the embryo. Seed were planted in either 18-by-18-by-36-cm pots filled with steam-pasteurized potting medium or steam-pasteurized potting medium later inoculated with a suspension of 186r. The potting medium was inoculated by thoroughly mixing the suspension of $186 \mathrm{r}$ into the medium by hand. To confirm final $186 \mathrm{r}$ populations, $10 \mathrm{~g}$ of infested media was suspended in $10 \mathrm{ml}$ of $\mathrm{sdH}_{2} \mathrm{O}$ which was vortexed for $2 \mathrm{~min}$ at high speed. The suspension then was serially diluted and plated on TSBA+rif plates which were incubated at $28^{\circ} \mathrm{C}$. Colonies were tallied and CFU/g potting media were determined $36 \mathrm{~h}$ later. The initial inoculum level was $2 \times 10^{7}$ $\mathrm{CFU}$ of 186r per gram potting medium. Three treatments were established: (i) seed inoculated with186r (SI), (ii) potting medium infested with 186r (PMI), and (iii) noninoculated seed and potting medium (negative control). Paradox seedlings were arranged in a completely randomized design and grown in a greenhouse $\left(30^{\circ} \mathrm{C}\right)$ for 180 days, after which half of the seedlings in each treatment were destructively sampled by sectioning the stem and primary root. The second half of the seedlings were wounded using a steri- lized grafting tool. A wound was made with the grafting knife $6 \mathrm{~cm}$ above the crown to determine whether a systemic A. tumefaciens population could cause crown gall at a stem wound site. The wound site and grafting tool were surface sterilized with $70 \%$ ethanol before each seedling was wounded. Cuts were approximately 3 $\mathrm{mm}$ deep. Wounds were immediately wrapped in Parafilm (Pechiney Plastic Packaging Company, Chicago) and plants were incubated in the greenhouse for 120 days. After the 120-day greenhouse incubation, wounded plants were placed in the dark at $6^{\circ} \mathrm{C}$ for 100 days to induce dormancy followed by 60 days of greenhouse incubation $\left(30^{\circ} \mathrm{C}\right)$. Gall formation at the stem wound site was recorded and seedling stem and roots were sectioned and tested for the presence of A. tumefaciens as described below. In the course of two trials, in total, 35, 15, and 35 Paradox seed were subject to the SI, PMI, and negative control treatments, respectively.

Seedling inoculation experiment. Seedling inoculation experiments were designed to emulate sources of inoculum encountered in production orchards. Two-year-old Paradox seedlings were transplanted into either steam-pasteurized potting media or steampasteurized potting media inoculated with strain 186r. The inoculated medium was prepared by thoroughly mixing a water suspension of strain 186r cells into the medium by hand. The potting medium was assayed by dilution plating on TSBA+rif as described above and shown to contain $186 \mathrm{r}$ at $7 \times 10^{7} \mathrm{CFU} / \mathrm{g}$ of potting media. During transplanting, the root system of all seedlings was scored by running a large knife down the main root three times. The resulting cuts entered the vascular steele. Seedlings were planted immediately after scoring, incubated in a greenhouse $\left(30^{\circ} \mathrm{C}\right)$ for 120 days, and subsequently forced into dormancy by incubation at $6^{\circ} \mathrm{C}$ for 120 days in the dark. Approximately 14 days after placement back into the greenhouse $\left(30^{\circ} \mathrm{C}\right)$, buds broke and leaves began to expand. At this time, all seedlings were wounded on the stem using a grafting knife dipped in a suspension of strain 186r $\left(7 \times 10^{7} \mathrm{CFU} / \mathrm{ml}\right)$ or a knife freshly sterilized in Physan 20 (Maril Products Incorporated, Tustin, CA) at 5,000 ppm. Wounds were made $6 \mathrm{~cm}$ above the crown in an area freshly surface sterilized with $70 \%$ ethanol. The four treatments included (i) 186r-inoculated soil and stem (soil/stem inoc), (ii) 186r-inoculated soil only (soil-inoc), (iii) 186r-inoculated stem only (stem-inoc), and (iv) noninoculated soil control with wounded roots and stems (negative control). At 70 days after stem wounding, all soil-inoc seedlings and half of the negative control seedlings were sectioned to detect the presence of A. tumefaciens. Stem-inoc and soil/stem inoc seedlings were wounded again higher on the stem with a grafting knife, as described above, using A. tumefaciens inoculum levels of $1 \times$ $10^{9} \mathrm{CFU} / \mathrm{ml}$. Gall development was recorded and seedling sectioning occurred after an additional 120 days of greenhouse incubation. Seedlings were arranged in a completely randomized design in the greenhouse. Two trials consisted of a total of 32 Paradox seedlings in each treatment.

Stem sectioning. To detect systemic A. tumefaciens populations, stems were removed, trimmed of leaves, and then surface sterilized in $70 \%$ ethanol for $30 \mathrm{~s}$. To confirm surface sterilization, $10 \%$ of the surface-sterilized stems, selected randomly, were rolled on TSBA plate which were incubated at $28^{\circ} \mathrm{C}$ for 3 days to check for microbial contamination. No bacteria were cultured from the surface-sterilized stems. Stems were sectioned into 5-cm segments, cut longitudinally with a sterile razor, and given a designation to indicate order from crown to apical meristem. One-half of each section was placed, cut surface down, on 1A (23) semiselective medium for Rhizobiaceae and amended with tellurite at $80 \mathrm{ppm}$, cyclohexamide (1A) at $100 \mathrm{ppm}$, and TSBA+rif to detect 186r. After $24 \mathrm{~h}$ at $28^{\circ} \mathrm{C}$, stem sections were slid to another unoccupied section of the agar surface. TSBA+rif was incubated for $48 \mathrm{~h}$ at $28^{\circ} \mathrm{C}$ and then at room temperature (approximately $25^{\circ} \mathrm{C}$ ) for an additional 5 days. $1 \mathrm{~A}$ was incubated for $72 \mathrm{~h}$ at $28^{\circ} \mathrm{C}$ and then at room temperature for an additional 4 days. Bacterial colonies were picked at first appearance, single colony purified on the same medium, tested for Ti-plasmid presence using Ti-plasmid-specific 
primers (Tip6), and checked for growth on TSBA+rif (45). Isolates determined not to be 186r were subject to Benedict's test and identified by sequencing the $16 \mathrm{~S}$ rDNA gene, which was amplified using universal primers fd6 and rp5 $(4,22,41)$. DNA sequencing was performed at the University of California, Davis Division of Biological Sciences Automated DNA Sequencing Facility (Davis, CA). 16S rDNA sequence data were analyzed using the University of Michigan Ribosomal Project (http://rdp.cme.msu.edu).

Root sectioning. To determine the presence of endophytic $A$. tumefaciens populations, a $7-\mathrm{cm}$ segment of the primary root, located at least $10 \mathrm{~cm}$ below the crown, was excised from each root system. The root segments were first trimmed of secondary roots, scraped with a sterile blade to remove the epithelial layer, and surface sterilized in $20 \%$ bleach for 20 min with agitation on a horizontal shaker. The exteriors of $10 \%$ of the surface-sterilized root sections were rolled on TSBA+rif to confirm surface sterilization as described above. No bacteria were cultured from surfacesterilized root sections. Surface-sterilized segments were cut longitudinally and placed onto TSBA+rif. Segments were incubated and colonies were identified using methods as described for stem sections.

Plant parameters. The branching system of the seedlings analyzed consisted only of a main stem with no lateral branches. Stem length and mass measurements were taken from the fresh weight of the main stem, from crown to apical meristem, including all leaves. Crown diameter was measured at the widest point between the stem and root system. Before measuring growth parameters, the root systems were first washed with water to remove potting media. Gall mass was measured by removing galls from the root or crown at the point of attachment to the plant. Root mass was a fresh weight measurement of all belowground parts except for the galls. Total plant mass is the sum of stem, root, and gall mass.

Statistical analysis. In both seed and seedling inoculation experiments, frequencies of A. tumefaciens isolation and gall development from all treatments were compared with each other using $\chi^{2}$ analysis. Significant differences were determined at a Bonferroni-adjusted significance level (33). Plant parameter measurements were subject to an analysis of variance using PROC GLM in SAS (SAS Institute Cary, NC). Variables were transformed to meet the assumptions of normality and homogeneity of variance by PROC RANK when necessary. Means were separated using Tukey's $w$ test (SAS Institute, Cary, NC).

\section{Results}

Seed inoculation experiment. In all, 94\% ( $n=35$ seedlings) and $93 \%$ ( $n=15$ seedlings) of SI and PMI seedlings, respectively, developed galls (Table 1). No galls developed on negative control seedlings, which was significantly different from gall development on inoculated seedlings $(P<0.0001)$. Most galls formed on the main tap root. Of the seedlings exhibiting galls ( $n=43$ seedlings), $98 \%$ had galls on the tap root, $2 \%$ formed a gall only at the crown, and $29 \%$ developed galls on the tap root and crown (Table 1). Approximately $82 \%$ of galls on the tap root occurred at the site of lateral root emergence. Seedlings with galls had an average of 13.8 galls per seedling. Galls observed before dormancy were composed of intact, pliant tissue typical of actively growing crown gall. Galls observed after dormancy were either composed of actively growing tissue or were rotten and sloughed off during sampling. Of 21 seedlings with galls observed post dormancy, $43 \%$ had visibly rotting galls.

Other than greater gall mass, seedlings originating from inoculated seed (SI and PMI) had growth parameters similar to seedlings originating from nontreated seed in the first season (Table 2). In the second season, seedlings from inoculated seed were significantly reduced in root mass and stem mass, stem length, and stem growth during the second season when compared with seedlings from nontreated seed. Gall mass was greater in SI and PMI seedlings but total plant mass was similar across all treatments. The crown diameter of SI and the negative-controltreated seedlings were greater than PMI-treated seedlings in the second season.

A. tumefaciens $186 \mathrm{r}$ was isolated from the interior of surfacesterilized stems in 91 and $87 \%$ of SI and PMI seedlings, respectively (Table 1). Two asymptomatic SI seedlings (post dormancy) and one asymptomatic PMI seedling (pre-dormancy) supported endophytic $186 \mathrm{r}$ populations. A. tumefaciens $186 \mathrm{r}$ was not detected inside the stem of one symptomatic SI seedling (post dormancy) and two symptomatic PMI seedlings (post dormancy). Internal 186r populations were never detected in the negative controls. Native avirulent $A$. tumefaciens strains were detected in 18,27 , and $34 \%$ of SI, PMI, and negative control seedlings, respectively. Seedlings grown from inoculated seed were less likely to harbor avirulent $A$. tumefaciens compared with noninoculated negative control seed as determined by $\chi^{2}$ analysis $(P<0.0001)$.

Table 1. Incidence of endophytic occurrence of Agrobacterium tumefaciens 186r and disease development in 'Paradox' hybrid walnut seedlings inoculated as seed $^{y}$

\begin{tabular}{|c|c|c|c|c|c|}
\hline \multirow[b]{2}{*}{ Treatment $^{\mathrm{z}}$} & \multicolumn{3}{|c|}{ A. tumefaciens detected (\%) } & \multicolumn{2}{|c|}{ Seedlings with galls (\%) } \\
\hline & Stems & Stem segments & Roots & At root/crown & At wound site \\
\hline SI & $91 *$ & $23^{*}$ & $100 *$ & $94 *$ & $20 *$ \\
\hline PMI & $87 *$ & $10^{*}$ & $100 *$ & $93 *$ & $13^{*}$ \\
\hline Negative control & 0 & 0 & 0 & 0 & 0 \\
\hline
\end{tabular}

${ }^{y}$ Asterisk (*) indicates significantly different from the negative control as determined by $\chi^{2}$ analysis of frequencies using a Bonferroni-adjusted significance value $(P \leq 0.025)$.

${ }^{\mathrm{z}} \mathrm{SI}=$ seed infested and $\mathrm{PMI}=$ potting media infested.

Table 2. Growth parameters of Paradox seedlings exposed to seed inoculation treatments ${ }^{\mathrm{x}}$

\begin{tabular}{|c|c|c|c|c|c|c|c|c|c|}
\hline Treatment $^{y}$ & Seasons $^{z}$ & $n$ & $\underset{(\mathrm{g})}{\text { Gall mass }}$ & $\begin{array}{l}\text { Root mass } \\
(\mathrm{g})\end{array}$ & $\underset{(\mathrm{g})}{\text { Stem mass }}$ & $\begin{array}{l}\text { Plant mass } \\
(\mathrm{g})\end{array}$ & $\begin{array}{l}\text { Total stem } \\
\text { height }(\mathrm{cm})\end{array}$ & $\begin{array}{l}\text { Second-year stem } \\
\text { growth }(\mathrm{cm})\end{array}$ & $\begin{array}{c}\text { Crown } \\
\text { diameter }(\mathbf{c m})\end{array}$ \\
\hline \multirow[t]{2}{*}{ SI } & $1 \mathrm{st}$ & 18 & $56 \mathrm{a}$ & 258 & 62 & 318 & 42 & & 1.8 \\
\hline & 2nd & 16 & 109 a & $280 \mathrm{~b}$ & $141 \mathrm{~b}$ & 530 & $95 \mathrm{~b}$ & $48 \mathrm{~b}$ & $2.275 \mathrm{a}$ \\
\hline \multirow[t]{2}{*}{ PMI } & 1st & 7 & $73 \mathrm{a}$ & 274 & 74 & 347 & 49 & $\ldots$ & 1.8 \\
\hline & 2nd & 8 & $116 \mathrm{a}$ & $223 \mathrm{~b}$ & $122 \mathrm{~b}$ & 461 & $90 \mathrm{~b}$ & $46 \mathrm{~b}$ & $1.75 \mathrm{~b}$ \\
\hline \multirow[t]{2}{*}{ Negative control } & $1 \mathrm{st}$ & 20 & $0 \mathrm{~b}$ & 262 & 78 & 341 & 46 & & 1.9 \\
\hline & 2nd & 17 & $0 \mathrm{~b}$ & 356 a & $233 \mathrm{a}$ & 591 & $119 \mathrm{a}$ & $71 \mathrm{a}$ & $2.6 \mathrm{a}$ \\
\hline
\end{tabular}

${ }^{\mathrm{x}}$ Letters indicate significant differences within pre- and post-dormancy time periods using Tukey's $w$. If no letter appears, no significant differences were detected using Tukey's $w$.

${ }^{\text {y }} \mathrm{SI}=$ seed infested and PMI $=$ potting media infested.

${ }^{\mathrm{z}} 1$ st season refers to the time period before first dormancy. 2 nd season refers to the time period after first dormancy. 
A. tumefaciens $186 \mathrm{r}$ was detected in 23 and $10 \%$ of the $5-\mathrm{cm}$ stem segments of SI and PMI-seedlings, respectively (Table 1). Strain 186r was detected in stem segments within $10 \mathrm{~cm}$ of the crown in $81 \%$ of the PMI and SI seedlings, and was detected after dormancy in the second season of growth in 55\% of the SI and PMI seedlings. Strain 186r was detected in root segments of all SIand PMI-treated seedlings (Table 1). Strain 186r was not detected in root segments of negative controls.

The stems of 17 SI, 8 PMI, and 16 negative control seedlings were wounded with a surface-sterilized blade and then forced into dormancy. Two SI seedlings with extensive galls in number and size died during dormancy. Of the remaining SI and PMI seedlings, $17 \%$ developed a gall at the wound site. All galls contained 186r. Galls did not form at the wound site on negative control seedlings.

Seedling inoculation experiment. A. tumefaciens detection and crown gall formation data from seedling inoculation experiments are presented in Table 3. In all, $81 \%(n=30)$ of seedlings wounded on the roots and planted in 186r-infested soil (soil-inoc and soil/stem inoc treatments) developed galls on the root or crown. Seedlings wounded and planted in noninoculated soil (stem-inoc and negative control treatments) did not develop galls on the roots or crown $(n=32)$.

Subterranean galls formed mainly on the tap root. However, galls were not obviously associated with wounds inflicted as part of the treatment. In total, $38 \%$ of galls were associated with lateral root initiation sites and at the crown near adventitious buds. Of the seedlings with subterranean galls, 93\% had galls on the tap root, $5 \%$ developed galls only on the crown, and $26 \%$ developed galls on the tap root and crown. If galls formed below ground, an average of 1.5 galls developed per seedling root system.

Eighteen days after being brought out of $6^{\circ} \mathrm{C}$ storage, buds broke and leaves started to expand. Sap exuded from stems wounded at this time. Then, 198 later, galls developed on 47 and $1 \%$ of the seedlings wounded with an inoculated blade as part of the stem-inoc and soil/stem inoc treatments, respectively. Twentyone days later, stem-inoc and soil/stem inoc seedlings were wounded again with an A. tumefaciens infested blade. At this time, wounds did not exude sap and galls formed on all inoculated seedlings 120 days later. Seedlings cut on the stem with a noninfested blade as part of the negative controls and soil-inoc treatments never developed galls at the wound site.
Growth parameters for seedlings in the soil-inoc treatment were recorded 84 days after dormancy. Compared with nontreated seedlings measured at the same time, soil-inoc seedlings had greater gall mass and reduced root mass, stem mass, plant mass, and stem length (Table 4). Growth parameters of soil/stem inoc and steminoc seedlings were measured 204 days after dormancy. Compared with nontreated seedlings measured at the same time, soil/stem inoc seedlings had reduced stem length and crown diameter. Steminoc seedlings had increased root mass and, hence, greater plant mass compared with negative controls.

A. tumefaciens $186 \mathrm{r}$ populations were detected in the surfacesterilized stems of 78, 93, and $93 \%$ of soil-inoc, stem-inoc, and soil/stem inoc seedlings, respectively. Strain 186r was not detected in surface-sterilized stem sections collected from negative controls. Noninoculated avirulent $A$. tumefaciens strains were detected in 19, 20,0 , and $43 \%$ of soil-inoc, stem-inoc, soil/stem inoc, and negative-control-treated seedlings, respectively. Strain 186r-inoculated seedlings were less likely to harbor avirulent $A$. tumefaciens than noninoculated negative control seedlings, as determined by $\chi^{2}$ analysis $(P=0.001)$.

A. tumefaciens $186 \mathrm{r}$ was detected in 19,16 , and $17 \%$ of stem segments from soil-inoc, stem-inoc, and soil/stem inoc treatments, respectively. Strain 186r was detected in the lowest $10-\mathrm{cm}$ stem segments closest to the crown in $80 \%$ of the seedlings. When only stems were inoculated, systemic populations of $186 \mathrm{r}$ were detected within $5 \mathrm{~cm}$ of the inoculation site in $83 \%$ of the seedlings tested. Only $20 \%$ of these seedlings had detectable 186 r populations beyond $5 \mathrm{~cm}$ of the inoculation site. Strain 186r was detected in root segments of all seedlings in the soil-inoc and soil/stem inoc treatments. Strain $186 \mathrm{r}$ was detected in the roots of $13 \%(n=15)$ of stem-inoc seedlings. These seedlings had detectable 186r populations in the stem as well. Strain 186r was not detected in any root segment of the negative controls.

\section{Discussion}

Establishment of a systemic microbial population in asymptomatic plant hosts has been demonstrated for many hosts and microorganisms $(3,30,32,38,40)$. Similarly, Agrobacterium sensu lato species also can be harbored within plant tissue $(4,5,8$ 10,12,13,18-20,31,35,42). The systemic movement of Agrobacterium spp. has been best studied in the A. vitis-grapevine pathosystem $(6,7,15-17,25,36)$. A. vitis can spread systemically in

Table 3. Incidence of endophytic occurrence of Agrobacterium tumefaciens 186r and disease development in Paradox hybrid walnut seedlings inoculated as seedlings ${ }^{y}$

\begin{tabular}{|c|c|c|c|c|c|}
\hline \multirow[b]{2}{*}{ Treatment $^{\mathrm{z}}$} & \multicolumn{3}{|c|}{ A. tumefaciens detected (\%) } & \multicolumn{2}{|c|}{ Seedlings with galls (\%) } \\
\hline & Stems & Stem segments & Roots & At root/crown & At wound site \\
\hline Soil-inoc & $88^{*}$ & $19 *$ & $100 *$ & $75^{*}$ & 0 \\
\hline Soil/stem inoc & $93^{*}$ & $17 *$ & $100 *$ & $93 *$ & $7 *$ \\
\hline Stem-inoc & $93 *$ & $16^{*}$ & $13 *$ & 0 & $47 *$ \\
\hline Negative control & 0 & 0 & 0 & 0 & 0 \\
\hline
\end{tabular}

y Asterisk (*) indicates significantly different from the negative control as determined by $\chi^{2}$ analysis of frequencies using a Bonferroni-adjusted significance value $(P \leq 0.016)$.

${ }^{\mathrm{z}}$ Treatments included 186r-inoculated soil only (soil-inoc), 186r-inoculated soil and stem (soil/stem inoc), 186r-inoculated stem only (stem-inoc), and noninoculated soil control with wounded roots and stems (negative control).

Table 4. Growth parameters of Paradox seedlings exposed to seedling inoculation treatments ${ }^{y}$

\begin{tabular}{|c|c|c|c|c|c|c|c|c|}
\hline Treatment $^{\mathrm{z}}$ & $n$ & $\begin{array}{c}\text { Gall mass } \\
(\mathrm{g})\end{array}$ & $\begin{array}{l}\text { Root mass } \\
(\mathrm{g})\end{array}$ & $\begin{array}{l}\text { Stem mass } \\
(\mathrm{g})\end{array}$ & $\begin{array}{l}\text { Plant mass } \\
(\mathrm{g})\end{array}$ & $\begin{array}{l}\text { Stem height } \\
\quad(\mathrm{cm})\end{array}$ & $\begin{array}{l}\text { Second-year stem } \\
\text { growth }(\mathbf{c m})\end{array}$ & $\begin{array}{c}\text { Crown } \\
\text { diameter }(\mathrm{cm})\end{array}$ \\
\hline Soil-inoc & 16 & $36^{*}$ & $464 *$ & $253 *$ & $717 *$ & $29 *$ & 39 & 2.6 \\
\hline Neg, soil-inoc & 8 & 0 & 620 & 317 & 937 & 36 & 36 & 2.9 \\
\hline Soil/stem inoc & 14 & $205 \mathrm{a}$ & $1,070 \mathrm{~b}$ & $241 \mathrm{a}$ & $1,311 \mathrm{~b}$ & $80 \mathrm{~b}$ & $53 \mathrm{a}$ & $3.2 \mathrm{~b}$ \\
\hline Stem-inoc & 15 & $0 \mathrm{~b}$ & $1,374 \mathrm{a}$ & $284 \mathrm{a}$ & $1,658 \mathrm{a}$ & $199 \mathrm{a}$ & $44 \mathrm{~b}$ & $8.6 \mathrm{a}$ \\
\hline Neg, soil/stem and stem-inoc & 8 & $0 \mathrm{~b}$ & $978 \mathrm{~b}$ & $291 \mathrm{a}$ & $1,269 \mathrm{~b}$ & $225 \mathrm{a}$ & $53 \mathrm{a}$ & $8.7 \mathrm{a}$ \\
\hline
\end{tabular}

y Asterisk (*) indicates significant differences between 186r-inoculated soil only (soil-inoc) and respective negative control (Neg) treatments. Letters indicate significant differences between 186r-inoculated soil and stem (soil/stem inoc), 186r-inoculated stem only (stem-inoc), and their respective control using Tukey's $w$.

$\mathrm{z}$ Treatments were measured at different phenological times and are compared with negative controls measured during the same period. 
grapevines $(6,15,16)$, with the primary inoculum in vineyards often coming from infested scion cuttings. A. vitis residing in vineyard soil is also capable of infecting roots and moving systemically in the vine $(15,16,28,36,38)$. The distribution of the bacterium in the stem is not continuous $(34,37)$ and the size of systemic populations fluctuates with the season $(2,26,28)$. A . vitis also resides within grapevine root tissue $(6,7,16,17,36,39)$. Lehoczky (17) hypothesized that $A$. vitis overwinters in grape roots and rapidly moves from roots into aerial parts of the plant with the surge of vascular fluid occurring when vines break dormancy in the spring. During the rest of the year, movement of A. vitis in grapevines is thought to be slow (34). Once internal populations of A. vitis are established, disease occurs where wounds, usually caused by freeze damage, occur on the grapevine $(15,16,38)$. The data presented here provide evidence that systemic presence and movement of $A$. tumefaciens in the walnut rootstock Paradox is similar to that of $A$. vitis in grapevines.

In this study, A. tumefaciens was consistently isolated from the root system of seedlings exposed to A. tumefaciens inoculum, suggesting that walnut root systems readily support endophytic populations of A. tumefaciens. Systemic A. tumefaciens populations were detected in $100 \%$ of the plants exposed to A. tumefaciens as seed. Systemic populations also were established in $100 \%$ of seedlings exposed to inoculum when transplanted into $A$. tumefaciens-infested soil. Additionally, 6 months after inoculation, A. tumefaciens was detected in the roots of $13 \%$ of the seedlings exposed to inoculum via stem wounding. The seemingly omnipresent A. tumefaciens population in walnut roots also lends support of the movement and recolonization process proposed by Lehoczky (17).

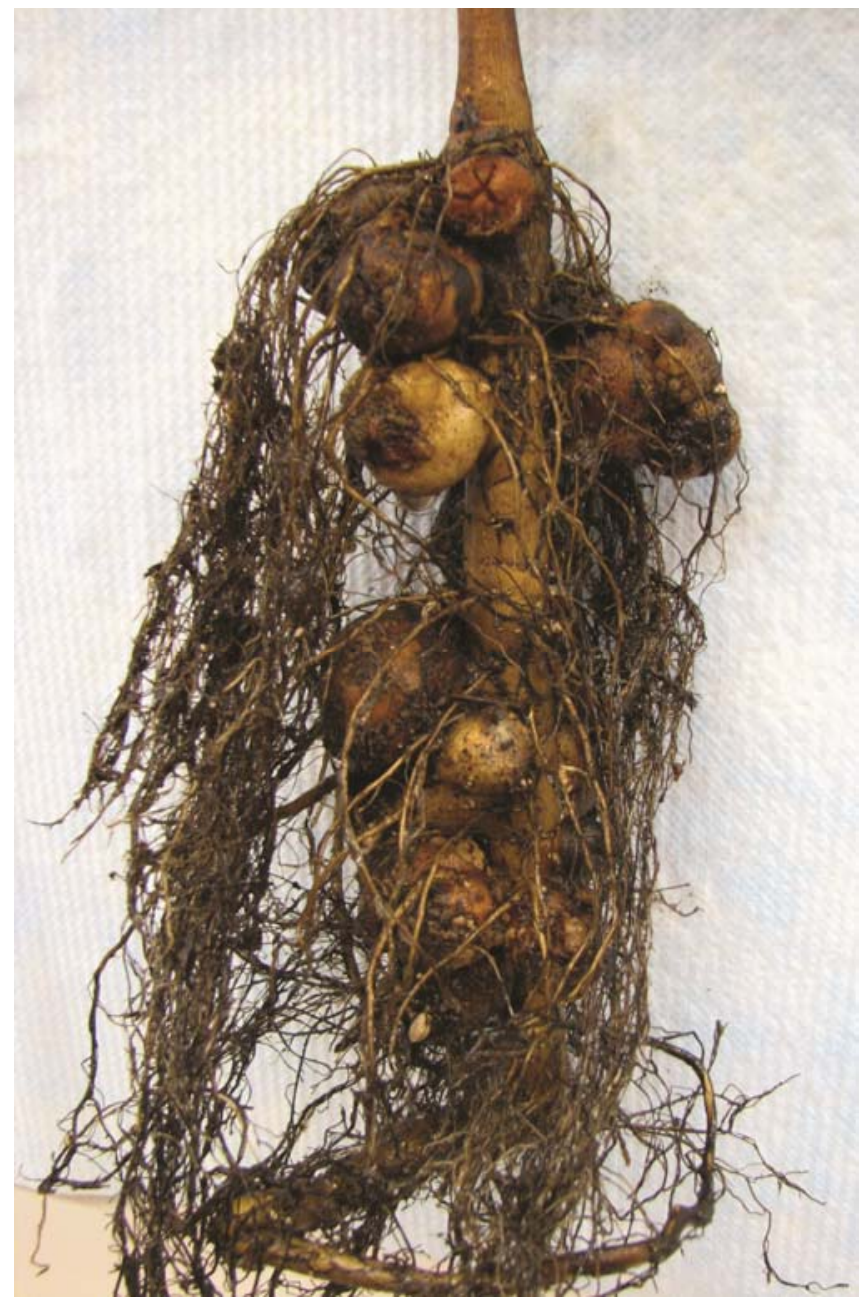

Fig. 1. Symptoms of crown gall caused by Agrobacterium tumefaciens on Juglans hindsii × Juglans regia 'Paradox' seedling grown from artificially inoculated seed.
During both the first and second seasons, A. tumefaciens was widely distributed throughout the stem of seedlings exposed to inoculum during germination. This implies that bacteria in young, developing plant tissue are easily transported to new growth with expansion of the original tissue. A. tumefaciens also can disperse from a point source in a seedling but movement may be slow. When stems were inoculated (stem-inoc), the bacterium was found only within $5 \mathrm{~cm}$ from the point source in $85 \%$ of the seedlings when assayed 3 months after initial inoculation. When roots were inoculated (root-only), A. tumefaciens was found in first- and second-season growth. The root-only seedlings were subject to the push of vascular fluid associated with post-dormancy spring flush. As proposed by Lehoczky (17), the push of vascular fluid helped distribute A. tumefaciens throughout the plant. However, A. tumefaciens populations were discontinuous along the stem, suggesting that either bacteria aggregate in the stems or population levels are generally low inside the stems, which makes detection difficult (29).

In this study, endophytic populations of avirulent $A$. tumefaciens biovar 1 were frequently detected in Paradox walnut seedlings. The systemic presence of native, avirulent strains of A. tumefaciens provides additional evidence of the ease with which clean planting stocks can be colonized by members of the native microflora, including A. tumefaciens.

Systemic populations of A. tumefaciens can cause crown gall. Of seedlings originating from $A$. tumefaciens-inoculated seed (SI and PMI seedlings), $17 \%$ developed galls at stem wounds made approximately 12 months after the seed were initially exposed to $A$. tumefaciens. The low incidence is most likely due to the observed random distribution of $A$. tumefaciens in the stem. In contrast, stem wounds on root-scored seedlings planted in infested soil (soil-inoc) did not result in gall formation although the seedlings were exposed to inoculum for more than 12 months and systemic populations were detected in the stem 2.5 months after the plants were stem wounded. SI seedlings were wounded before dormancy, whereas soil-inoc seedlings were wounded shortly after dormancy. Similar to the hypothesis proposed by Lehoczky (17), A.

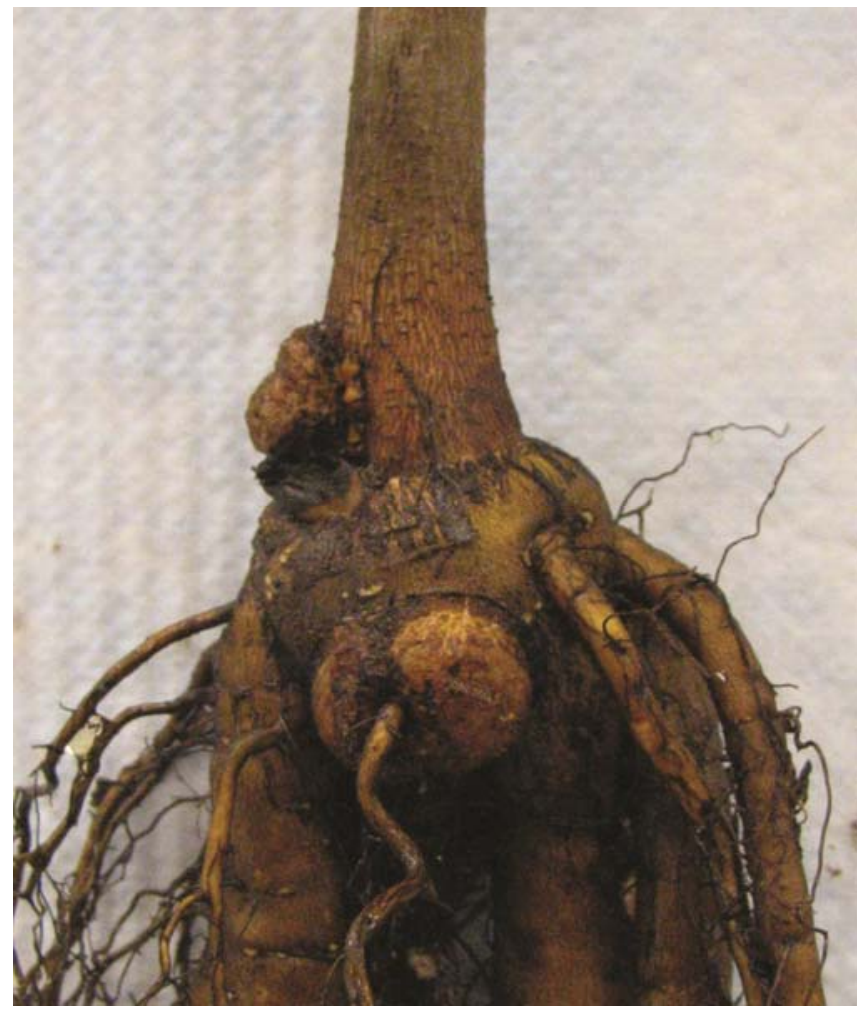

Fig. 2. Gall formation at the site of lateral root emergence on Juglans hindsii $x$ Juglans regia 'Paradox' seedling grown in Agrobacterium tumefaciens artificially inoculated soil. 
tumefaciens stem populations would be high before dormancy and low during and soon after dormancy, thus explaining the difference in gall development observed between SI- and root-only-treated seedlings. These data suggest that $A$. tumefaciens populations fluctuate in Paradox stems in a way similar to that reported for $A$. vitis in grapevines (17).

Disease incidence also may be affected by seasonal host susceptibility. When stem-inoc and soil/stem-inoc seedlings were wounded while breaking dormancy and inoculated with high levels of A. tumefaciens $\left(1 \times 10^{8} \mathrm{CFU} / \mathrm{ml}\right)$, only $28 \%$ of the seedlings developed galls. In contrast, $100 \%$ of these same plants, inoculated 3 weeks later in a similar fashion, developed galls. This suggests that susceptibility to A. tumefaciens is dramatically affected by host phenology. The first wound inoculation occurred while the seedlings were emerging from dormancy, the stage when grafting usually occurs in walnut production. Sap was observed "bleeding" from these wounds soon after wounding. This bleeding process may serve to flush the wound and limit the establishment of $A$. tumefaciens. Bleeding was not observed when wounds were made 3 weeks later, during subsequent wound inoculation.

Walnut seedlings can be asymptomatic and still harbor populations of virulent $A$. tumefaciens. In this study, $7 \%$ of the seedlings with systemic $A$. tumefaciens populations did not develop galls. Additionally, after dormancy, galls appeared to have rotted and sloughed off. During the process of harvesting 2-year-old dormant walnut seedlings in nurseries, the plants have significant portions of their root system removed and are shaken to dislodge remaining soil. Rotten gall tissue is likely to be dislodged as well. Therefore, visually asymptomatic trees supporting systemic A. tumefaciens populations could inadvertently enter the trade.

Seed exposed to virulent $A$. tumefaciens prior to germination resulted in seedlings riddled with galls, mainly on the roots and occasionally on the crown (Fig. 1). On average, seed exposed to $A$. tumefaciens developed 13.8 galls/seedling. The effects of these galls on plant growth were not measurable in the first growing season but resulted in smaller root systems and less vigorous stem growth in the second season (Table 3). Plant mass was similar across inoculated and noninoculated treatments, demonstrating that plant resources normally allocated to healthy tissue growth were diverted to gall formation. At the end of the second season, the root systems of inoculated seedlings were $29 \%$ smaller. The stems of inoculated seedlings were $22 \%$ shorter and $43 \%$ lighter. Crown diameter was reduced only in PMI treatment, which may be due to exposure to a higher initial concentration of inoculum.

Paradox seedlings, under these experimental conditions, developed 1.5 galls/seedling. Paradox seedlings inoculated with $A$. tumefaciens on the roots (soil-inoc and soil/stem-inoc) were reduced in second-season stem growth and, hence, overall stem length by approximately $20 \%$ (Table 4). In soil-inoculated treatments, the effects of crown gall are more apparent on soil-inoc seedlings compared with soil/stem inoc seedlings (Table 4). The differences are likely due to the differences in plant phenology when the treatments were assayed. Stem-inoc Paradox seedlings were not reduced in root or shoot growth compared with the negative control and, were greater in root and plant mass for reasons unknown. In the seedling stage, gall formation on the root/crown had a greater effect of plant growth than gall formation on the stem.

It is important to note that galls rarely formed at the wounds produced by root scoring prior to inoculum exposure. The majority of galls formed at lateral root initiation sites where tap-root tissue split during secondary root emergence (Fig. 2). Adventitious shoots located close to the soil line also were prone to gall development. Seed exposed to A. tumefaciens were more prone to developing galls at root initiation points compared with plants exposed to $A$. tumefaciens as seedlings. This is likely due to a higher number of secondary roots forming during the first season of seedling development. Management practices reducing man-made wounds may be helpful in reducing root-gall development but it seems that most wounds which provide A. tumefaciens infection courts occur during natural root growth.
The data presented here indicate that $A$. tumefaciens can readily infect, colonize, and survive endophytically in the internal tissues of walnut tree stems and roots. Initial sources of these endophytic populations can be found on the seed husks or shell surfaces, adjacent soil, and infested cutting tools (44). Asymptomatic Paradox seedlings also can harbor significant virulent and avirulent $A$. tumefaciens populations. The distribution of A. tumefaciens in the stem is not continuous and population levels may experience seasonal fluctuations. These insights into the ecology and epidemiology of A. tumefaciens are providing valuable information to aid in the development of enhanced crown gall management strategies for a wide variety of tree crop industries.

\section{Acknowledgments}

This work was supported by the United States Department of AgricultureAgricultural Research Service CRIS 5306-22000-14-00D.

\section{Literature Cited}

1. Agrios, G. N. 2005. Plant Pathology, 5th ed. Elsevier Academic Press, San Diego, CA.

2. Bauer, C., Schulz, T. F., Lorenz, D., Eichhorn, K. P., and Plapp, R. 1994 Population dynamics of Agrobacterium vitis in two grapevine varieties during the vegetation period. Vitis 33:25-29.

3. Bell, C. R., Dickie, G. A., Harvey, W. L. G., and Chan, J. W. Y. F. 1995. Endophytic bacteria in grapevine. Can. J. Microbiol. 41:46-53.

4. Bouzar, H., Chilton, W. S., Nesme, X., Dessaux, Y., Vaudequin, V., Petit, A. Jones, B., and Hodge, N. C. 1995. A new Agrobacterium strain isolated from aerial tumors on Ficus benjamina L. Appl. Environ. Microbiol. 61:6573.

5. Braun, A. C. 1941. Development of secondary tumors and tumor strands in the crown gall of sunflowers. Phytopathology 31:135-149.

6. Burr, T., and Katz, B. H. 1983. Isolation of Agrobacterium tumefaciens biovar 3 from grapevine galls and sap, and from vineyard soil. Phytopathology 73:163-165.

7. Burr, T., and Katz, B. H. 1984. Grapevine cuttings as potential sites of survival and means of dissemination of Agrobacterium tumefaciens. Plant Dis. 68:976-978.

8. Chilton, M. D., Currier, S., Farrand, S., Bendich, A., Gordon, M. P., and Nester, E. W. 1974. Agrobacterium tumefaciens DNA and PS8 bacteriophage DNA not detected in crown gall tumors. Proc. Natl. Acad. Sci. USA 71:3672-3676.

9. Cubero, J., Lastra, B., Salcedo, C. I., Piquer, J., and Lopez, M. M. 2006. Systemic movement of Agrobacterium tumefaciens in several plant species. J. Appl. Microbiol. 101:412-421.

10. El-Khalifa, M. D., El-Nur, E. E., Lippincott, B. B., and Lippincott, J. A 1973. Crown gall on castor bean leaves: the formation of secondary tumors. J. Exp. Bot. 24:1117-1129.

11. Flint, M. L., ed. 2003. Integrated Pest Management for Walnuts. Publication 3270. Statewide Integrated Pest Management Program, University of California Division of Agriculture and Natural Resources, Oakland.

12. Hill, J. B. 1928. The migration of Bacterium tumefaciens in the tissue of tomato plants. Phytopathology 18:553-565.

13. Hill, J. B, Brittingham, W. H., Gibbons, F. P., and Watts, G. W. 1930. Further notes on Bacterium tumefaciens and its host relationship. Phytopathology 20:179-186.

14. Jones, J. B., and Raju, B. C. 1988. Systemic movement of Agrobacterium tumefaciens in symptomless stem tissue of Chrysanthemum morifolium. Plant Dis. 72:51-54.

15. Lehoczky, J. 1968. Spread of Agrobacterium tumefaciens in the vessels of the grapevine, after natural inoculation. Phytopathol. Z. 63:239-246.

16. Lehoczky, J. 1971. Further evidences concerning the systemic spreading of Agrobacterium tumefaciens in the vascular systems of grapevines. Vitis 10:215-221.

17. Lehoczky, J. 1978. Root-system of the grapevine as a reservoir of Agrobacterium tumefaciens cells. Pages 239-243 in: Proc. 4th Int. Conf. Plant Pathol. Bacteriol.

18. Lippincott, J. A., and Heberlein, G. T. 1965. The quantitative determination of infectivity of Agrobacterium tumefaciens. Am. J. Bot. 52:856-863.

19. Marti, R., Cubero, J., Daza, A., Piquer, J., Salcedo, C. I., Morente, C., and Lopez, M. M. 1999. Evidence of migration and endophytic presence of Agrobacterium tumefaciens in rose plants. Eur. J. Plant Pathol. 105:39-50.

20. Miller, H. N. 1975. Leaf, stem, crown, and root galls induced in Chrysanthemum by Agrobacterium tumefaciens. Phytopathology 65:805811 .

21. Miller, M., Moore, L., and Dierenfeld, L. 1999. Survival of crown gall bacteria in almond, apple, cherry, pear, and walnut rootstocks. Calif. Walnut Res. Rep.

22. Moore, L. W., Bouzar, H., and Burr, T. 2001. Agrobacterium. Pages 17-35 in: Laboratory Guide for the Identification of Plant Pathogenic Bacteria, 3rd ed. N. W. Schaas, J. B. Jones, and W. Chun, eds. American Phytopathological Society, St. Paul, MN. 
23. Mougel, C., Cournoyer, B., and Nesme, X. 2001. Novel tellurite-amended media and specific chromosomal and Ti plasmid probes for direct analysis of soil populations of Agrobacterium biovars 1 and 2. Appl. Environ. Microbiol. 67:65-74.

24. Ogawa, J. M., and English, H. 1991. Diseases of Temperate Zone Tree Fruit and Nut Crops. Publication 3345. University of California Division of Agriculture and Natural Resources, Oakland.

25. Ophel, K., and Kerr, A. 1990. Agrobacterium vitis sp. Nov. for strains of Agrobacterium biovar 3 from grapevines. Int. J. Syst. Bacteriol. 40:236-241.

26. Peduto, F., Marchi, G., and Surico, G. 2010. Indexing Agrobacterium vitis in asymptomatic grapevine propagation material by two nested PCR assays. Am. J. Enol. Vitic. 61:102-112.

27. Pionnat, S., Keller, H., Hericher, D., Bettachini, A., Dessaux, Y., Nesme, X., and Poncet, C. 1999. Ti plasmids from Agrobacterium characterize rootstock clones that initiated spread of crown gall disease in Mediterranean countries. Appl. Environ. Microbiol. 65:4197-4206.

28. Pu, X. A., and Goodman, R. N. 1993. Effects of fumigation and biological control on infection of indexed crown gall free grape plants. Am. J. Enol. Vitic. 44:241-248.

29. Puopolo, G., Raio, A., and Zoina, A. 2007. Early detection of Agrobacterium tumefaciens in symptomless artificially inoculated chrysanthemum and peach plants using PCR. J. Plant Phytopathol. 89:185-190.

30. Ramos, D. E., ed.) 1998. Walnut Production Manual. Publication 3373. University of California Division of Agriculture and Natural Resources, Oakland.

31. Riker, A. J. 1923. Some relations of the crown gall organism to its tissue. J. Agric. Res. 25:119-132.

32. Rosenblueth, M., and Martinez-Romero, E. 2006. Bacterial endophytes and their interactions with hosts. Mol. Plant-Microbe Interact. 19:827-837.

33. Steel, R. G. D., Torrie, J. H., and Dickey, D. A. 1997. Principles and Procedures of Statistics a Biometrical Approach, 3rd ed. WCB/McGraw-Hill, St. Louis.

34. Stover, E. W., Swartz, H. J., and Burr, T. J. 1997. Endophytic Agrobacterium in crown gall-resistant and susceptible Vitis genotypes. Vitis 36:21-26.

35. Suit, R. F., and Eardley, E. A. 1935. Secondary tumor formation on herba- ceous hosts induced by Pseudomonas tumefaciens. Sci. Agric. 15:345-357.

36. Sule, S. 1986. Survival of Agrobacterium tumefaciens in Berlandieri $\times$ Riparia grapevine rootstock. Acta Phytopathol. Entomol. Hung. 21:203206.

37. Szegeti, E., and Bottka, S. 2002. Detection of Agrobacterium vitis by polymerase chain reaction in grapevine bleeding sap after isolation on a semiselective medium. Vitis 41:37-42.

38. Tarbah, F. A., and Goodman, R. N. 1987. Systemic spread of Agrobacterium tumefaciens biovar 3 in the vascular system of grapes. Phytopathology 77:915-920.

39. Theis, K. L., Griffin, D. E., Graves, C. H., and Hedgewood, C. P. 1991. Characterization of Agrobacterium isolates from muscadine grape. Plant Dis. 75:634-637.

40. Tyler, H. L., and Triplett, E. W. 2008. Plants as a habitat for beneficial and/or human pathogenic bacteria. Annu. Rev. Phytopathol. 46:53-73.

41. Weisburg, W. G., Barns, S. M., Pelletier, D. A., and Lane, D. J. 1991. 16S ribosomal DNA amplification for phylogenetic study. J. Bacteriol. 173:697703.

42. Weller, S. A., Simpkins, S. A., Stead, D. E., Kurdziel, A., Hird, H., and Weekes, R. J. 2002. Identification of Agrobacterium spp. Present within Brassica napus seed by TaqMan PCR, implications for GM screening procedures. Arch. Microbiol. 178:338-343

43. Yakabe, L. E., Parker, S. R., and Kluepfel, D. A. 2010. Effect of pre-plant soil fumigants on Agrobacterium tumefaciens, pythiaceous species, and subsequent soil recolonization by A. tumefaciens. Crop Prot. 29:583-590.

44. Yakabe, L. E., Parker, S. R., and Kluepfel, D. A. 2012. Cationic surfactants: Potential surface disinfectants to manage Agrobacterium tumefaciens biovar 1 contamination of grafting tools. Plant Dis. 96:409-415.

45. Yakabe, L. E., Maccree, M. M., Sudarshana, P., McClean, A. E., Parker, R., Wechter, W. P., Presting, G., Marutani-Hert, M., and Kluepfel, D. A. 2012. Novel PCR primers for detection of genetically diverse virulen Agrobacterium tumefaciens biovar 1 strains. J. Gen. Plant Pathol. 78:121 126.

46. Zoina, A, Raio, A., Peluso, R., and Spasiano, A. 2001. Characterization of agrobacteria from weeping fig (Ficus benjamina). Plant Pathol. 50:620-627. 